\title{
TELEMEDICINE DURING COVID 19 - A USEFUL TOOL IN COPD PATIENT MANAGEMENT
}

\author{
Florin Mihălțan ${ }^{1}$, Corina Oprea ${ }^{1}$, Valentin Coșei ${ }^{1}$, Bogdan Mut $^{2}$, Ancuța Constantin $^{1}$ \\ ${ }^{1}$ U.M.F. "Carol Davila", Bucharest \\ ${ }^{2}$ Cardioprevent
}

\begin{abstract}
Telemedicine has always had an openness to the diagnosis and treatment of respiratory diseases. Over the years, pros and cons arguments have been found to mark the benefits or disadvantages of using this tool for COPD patients. We initiated this remote monitoring activities on a small series of patients before the outbreak of the COVID19 epidemic, and this allowed us during these months of physical and social distance to point out the advantages of this method and also determined us to make a transition to review of the latest data in the field related to these types of interventions.
\end{abstract}

Keywords: COPD, telemedicine, quarantine.

\section{Rezumat}

Telemedicina a avut întotdeauna deschidere pentru diagnosticarea și tratamentul bolilor respiratorii. De-a lungul anilor s-au găsit argumente pro/contra pentru a marca beneficiile sau dezavantajele acestui instrument în cazul bolnavului cu BPOC. Inițierea de către noi a acestei monitorizări la distanță a unei serii mici de pacienți, integrați anterior exploziei epidemiei cu COVID19, ne-a permis, pe parcursul acestor luni de distanțare fizică și socială, să punctăm avantajele acestei metode și, de asemenea, ne-a determinat să facem o trecere în revistă a ultimelor date în domeniu, legate de aceste tipuri de intervenții.

Cuvinte cheie: BPOC, telemedicină, carantină. 


\section{INTERNAL}

\section{Original papers}

\section{Introducere}

Telemedicine is the use of telecommunication and information technology to provide clinical health care from a distance. It has been used to overcome distance barriers and to improve access to medical services that would often not be consistently available in distant communities ${ }^{(1)}$. There are many trials, completed or ongoing, for implementation of different methods of remote monitoring, at home, for COPD patients. Most of them are using pulse oximetry ( $\mathrm{SpO} 2)$, heart rate (HR), blood pressure (BP), and spirometry measurements in telemonitoring as approach for early prevention of COPD exacerbations. Correlated with early intervention and rapid response, associated telemedicine may have beneficial effects, with important reductions in use of services: hospital admissions/re-admissions, length of hospital stay, and emergency department, visits typically declined ${ }^{(2)}$.

\section{Protocols, materials and methods}

Before being "pampered" with the Romanian pandemic version of COVID19, we started a small telemonitoring project for patients with COPD (approved by the Ethics Commission of the National Institute of Pneumology and with the written consent of patients). The project implies spirometry and pulse oximeters measurements with electronic devices, then transmitted through the programs made available on the android phone to the surveillance and monitoring center. Also, we monitored their physical activity: the number of steps performed daily by the patient, the walking distance, but also support them when stalemate.

Subsequently, the remote monitoring of patients allowed us to visualize, live, the behavioral lifestyle for 3 patients before and during the official quarantine period and decide to synthesize the data obtained for approximately 3 months of monitoring. We mention that the emergency state that enforces physical and social distance had effects in Romania on March 14, 2020.

\section{Case No. 1}

B.I, a 68-years-old male patien, heavy smoker (40 pack-years), he quit 9 years ago, otherwise unremarkable exposure, personal pathological history of a COPD diagnosed in 2012- undergoing treatment with triple therapy: long-acting anticholinergic (LAMA) + long-acting beta 2 adrenergic (LABA) + inhaled corticosteroid (ICS) and essential hypertension under treatment;

T0: time of integration in the Telemedicine Project, on February 6, 2020, it was a stage II COPD GOLD, B (1 exacerbation per year) that clinically had 
dyspnea at moderate-high efforts, being stable hemodynamically and respiratory (BP 130/80 mmHg, $\mathrm{HR}=85 \mathrm{bpm}$, regular, Sa O2 = $96 \%$ aa, no added lung rales).

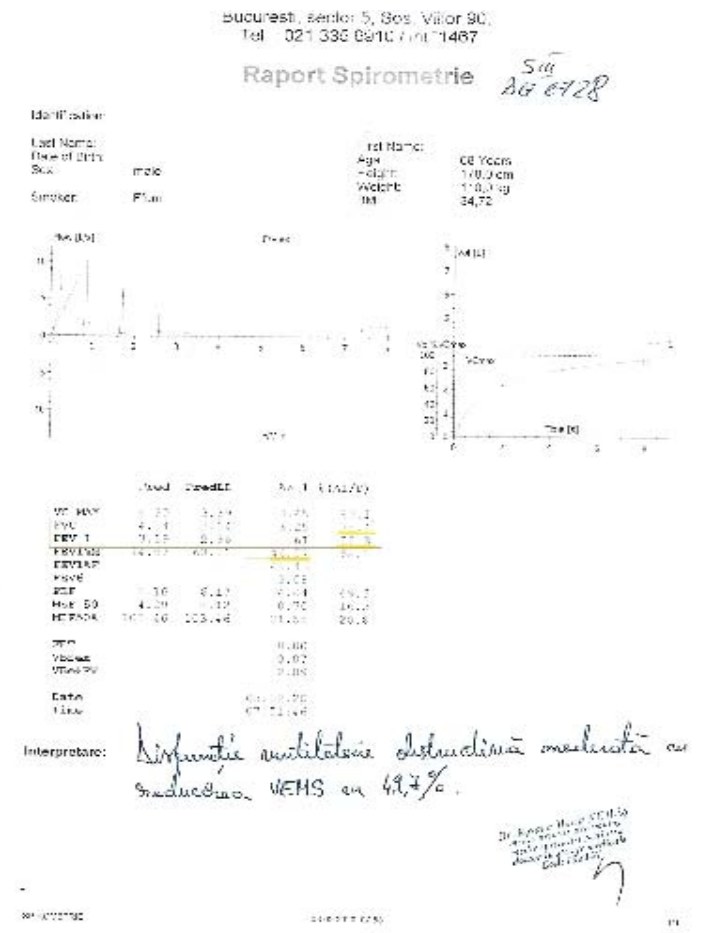

Figure 1. Spirometry

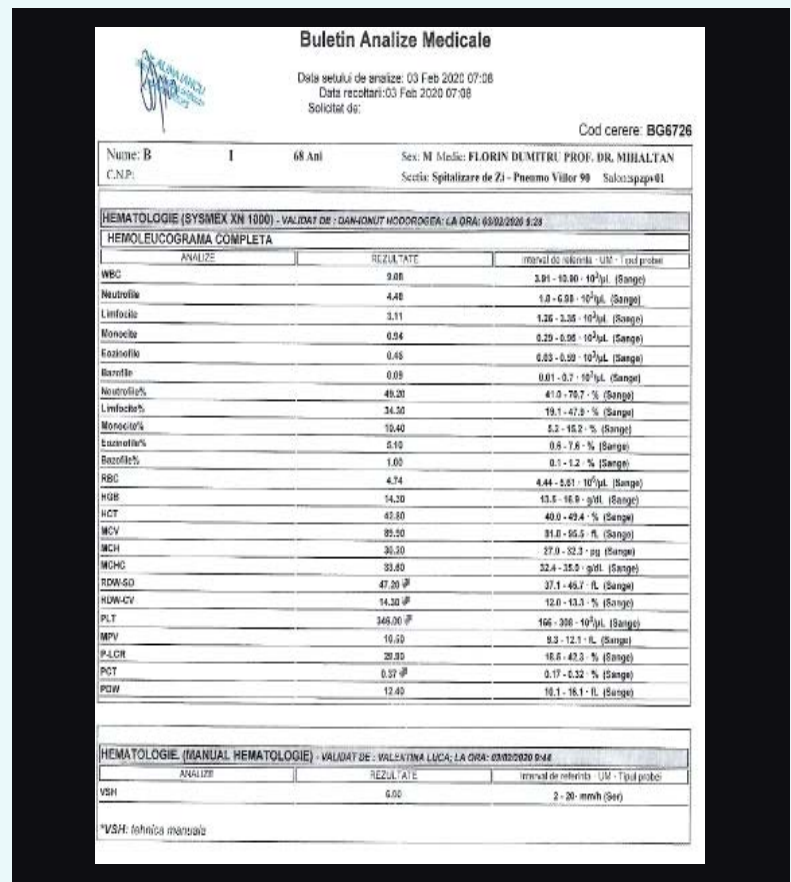

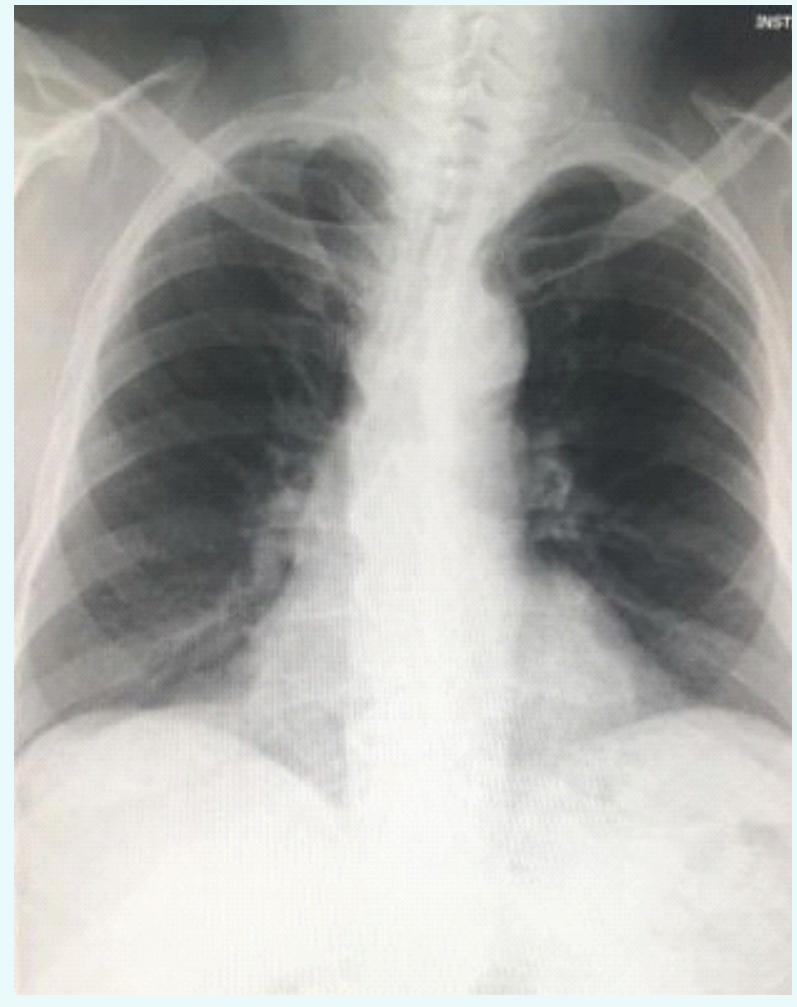

Figure 3. X-Ray evaluation

He had $\mathbf{C A T}$ score $<10$, m $\boldsymbol{M} \boldsymbol{R} \boldsymbol{C}$ score: 1 , and the rest of the paraclinical examinations were registered at respiratory functional tests as fallows (FRT) (Figure 1): $\mathrm{FVC}=(3.25$ L) $78.4 \%$; FEV $1=(1.61 \mathrm{~L}$ ) $50.3 \%$; IT $=46.57 \%$. Biologically (Figure 2) it was within normal limits (without inflammatory syndrome, without anemic syndrome) and radiologically (Figure 3): no evolutionary pleuro-pulmonary lesions.

The evolution of the respiratory functional parameters (Figure $4 a, b, c$ ) shows slight a tendency to increase, with a FEV1 that slowly grows to 2.6-2.8L. In the same time we noticed a variable walking distance, practically a physical activity with a visible decreasing tendency after the governmental ordinance of social distancing and quarantine came into force (Figure 5).

Figure 2. Biological report 


\section{INTERNAL MEDI}

\section{Original papers}

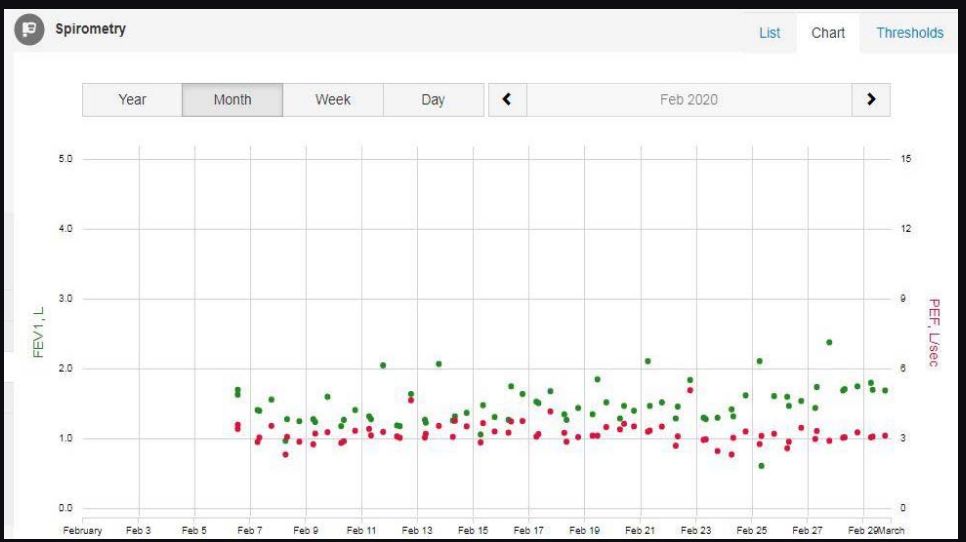

Figure 4a. February

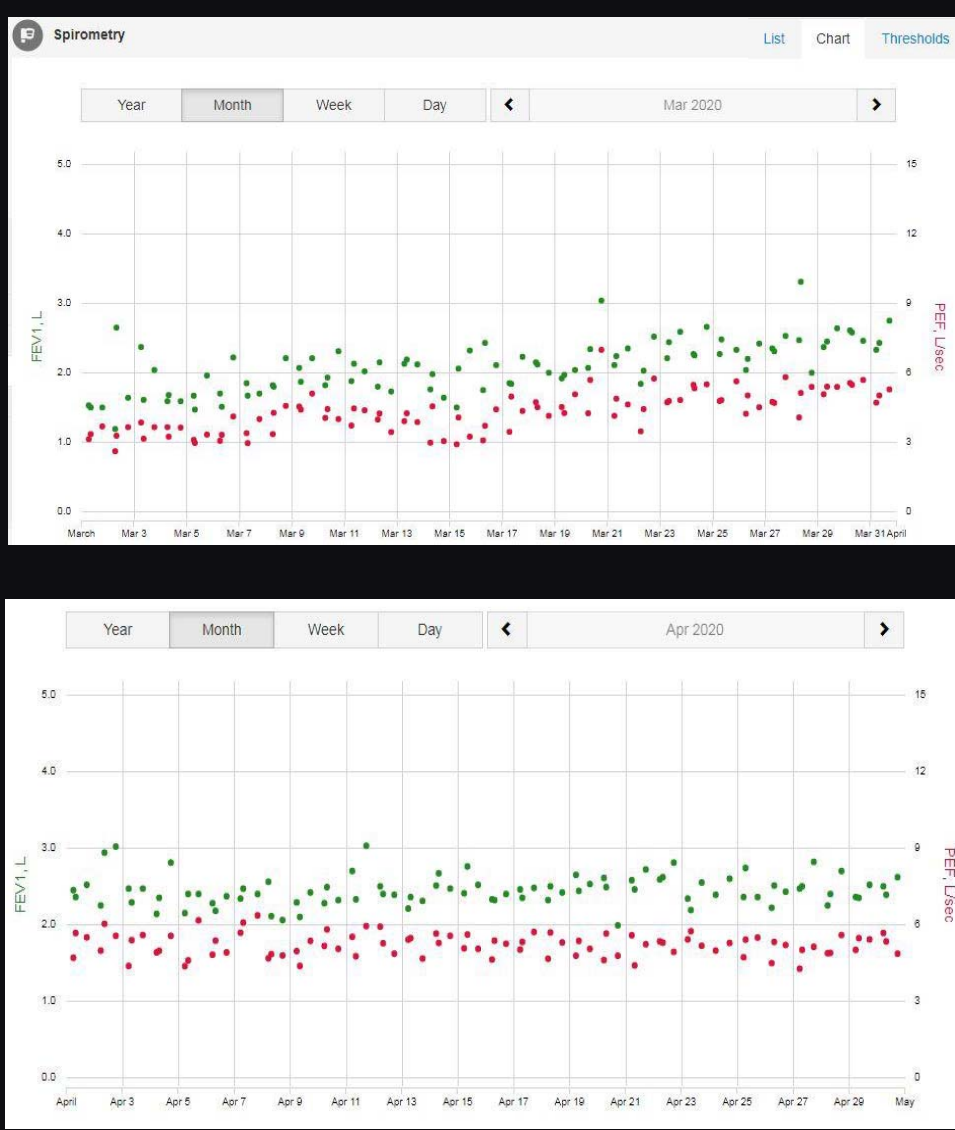

Figure 4b. March

Figure 4c. April 


\section{Distance}

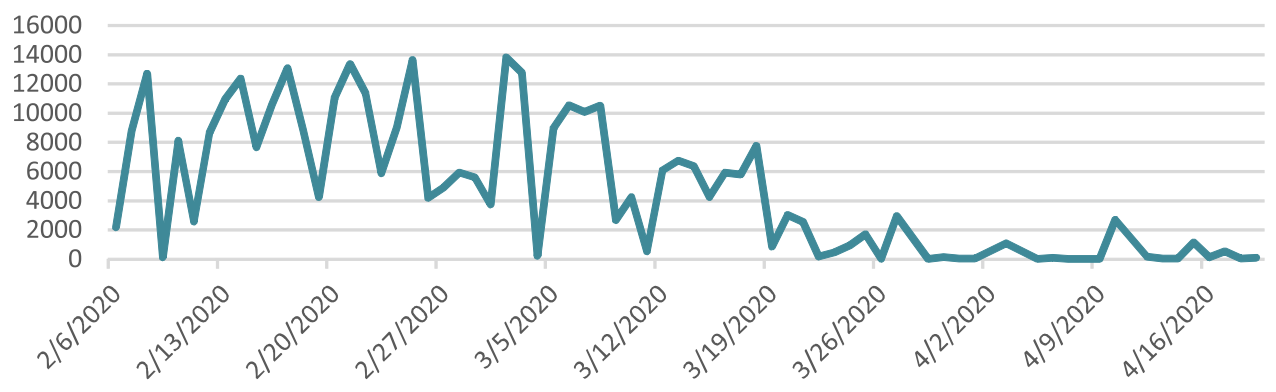

Figure 5. Physical activity monitoring

\section{Case No. 2}

L.R, a 45-years-old male patient, smoking tobacco 70 pack years, with no exposure to respiratory toxins, personal pathological history consisting of multiple comorbidities: Type II diabetes; hypertension grade III very high risk group; Morbid obesity and OSA under observation.

On T0 time, when the patient was added to our Telemedicin project, he was known diagnosed with COPD stage II GOLD, B (1 exacerbation per year) and was under a combination of long-acting anticholinergic and long-acting beta 2 adrenergic; clinically: dyspnea at low exertion, night snoring, pauses in breathing during sleep, morbid obesity (BMI $=43.94 \mathrm{kG} / \mathrm{m} 2$ ) and pulmonary, a bilateral vesicular murmur, without added lung rallies. The initial evaluation releves the presence a Sa $\mathrm{O} 2$ of $97 \%$ aa, with BP $145 / 90 \mathrm{mmHg}$ and an AV = 88 bpm, regular. He also had CAT score: $<10$ and MMRC score: 2. Paraclinically the initial data showed a: PFR (Fig.6): FVC $=(3.73$ L) $84.8 \%$; FEV $1=(2.39$ L) $66.3 \%$; IT $=$ 63.29\% PostBD: FVC = (3.75 L) 85.3\%; FEV 1 $=(2.58 \mathrm{~L}) 71.7 \%$; IT $=66.01 \%$, biologically: leukocytosis, without inflammatory syndrome, without anemic syndrome and radiological (Figure 7): cardiomegaly and accentuated bilateral infrahilar peribronhovascular pattern.

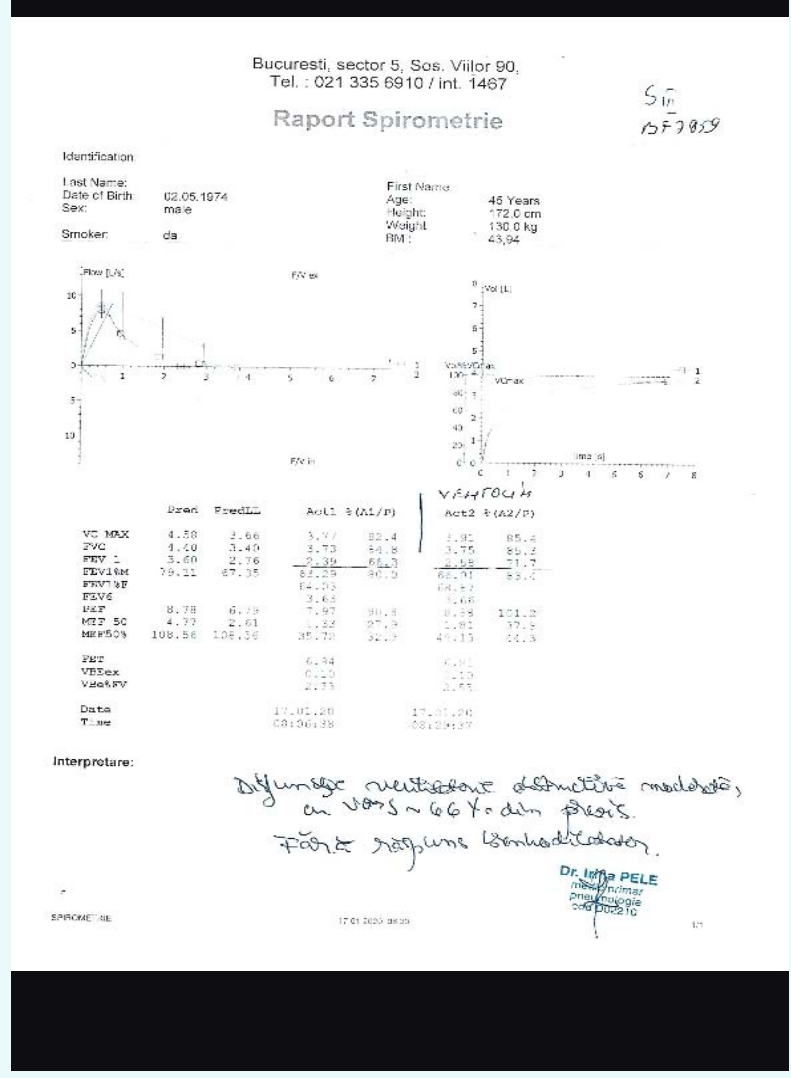

Figure 6. Spirometry 


\section{INTERNAL}

\section{Original papers}

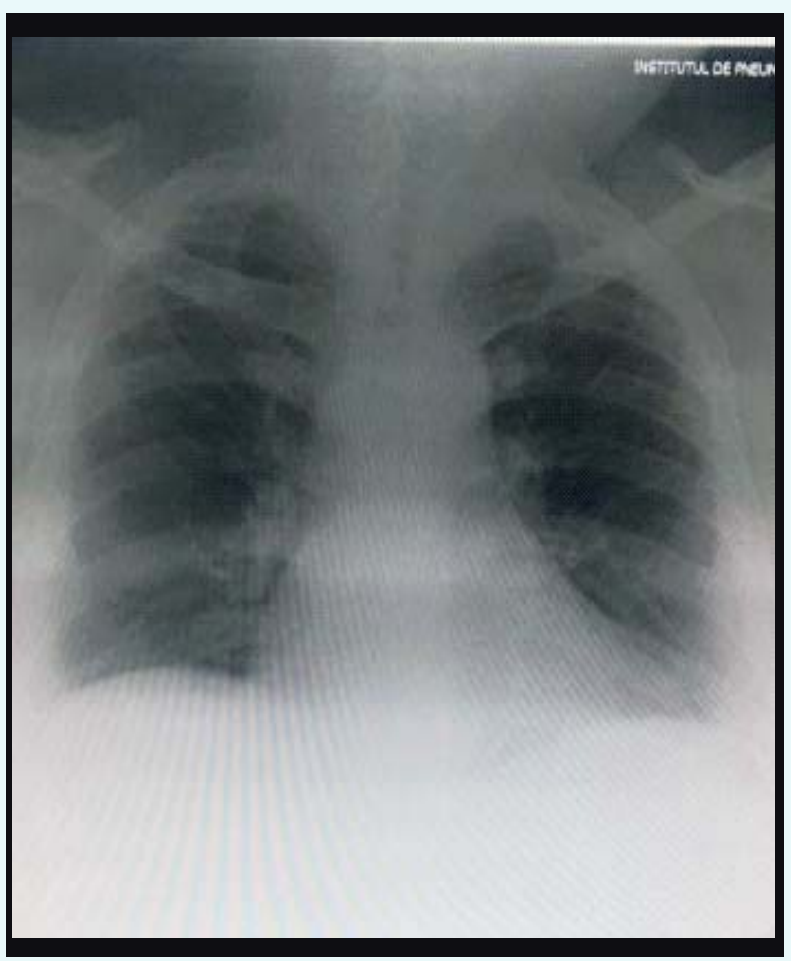

Figure 7. X-Ray evaluation

The evolution of respiratory functional parameters was also interesting over the 2 $1 / 2$ months (Figure $8 a, b, c$ )

Monitoring showed a patient with stationary respiratory function but also a period of noncompliance for almost 3 weeks.

Physical activity monitoring (Figure 9) also demonstrated a decrease in the number of steps taken, cased by the enforce of quarantine, to less than 500 steps.

\section{Case No. 3}

G.B.E, a 66-years-old male patien, history of smoking tobacco use 60 pack years, he quit 15 years ago, personal pathological history of COPD stage IV GOLD risk group D- Longterm oxygen therapy (LTOT); Moderate OSA CPAP / BIPAP, hypertension under treatment, anxiety syndrome and a history of recurrent atrial fibrillation, chronic ischemic coronary heart disease.

To, time of integration in the Telemedicine Project: for stage IV COPD GOLD group $D$, had a maximum treatment LABA + LAMA, ICS, theophylline, Roflumilast, long-term oxygen therapy $1.5 \mathrm{l} / \mathrm{min} 17 \mathrm{~h} / 24$. Clinically the presence of dyspnea at minimal exertion, episodes of nocturnal paroxysmal dyspnea; productive cough with mucopurulent sputum and pulmonary presents bilateral vesicular murmur, bilateral diffuse bronchial rales, a Sa $\mathrm{O} 2=93 \%$ in ambient air, a $\mathrm{BP}$ of $115 / 70 \mathrm{mmHg}$ and ventricular rate 62 bpm, regular pulse. Initially CAT score > 30; MMRC score: 4 Paraclinically had the following values of PFR (Figure 10): FVC = (2.46 L) $65.7 \%$; FEV $1=(0.93$ L) $32.1 \%$; IT = $36.67 \%$, PostBD: FVC $=(2.50$ L) $66.8 \%$; FEV 1 $=(0.99 \mathrm{~L}) 34 \%$; IT $=39.59$. Biological (Figure 11): present leukocytosis and biological inflammatory syndrome and radiological (Figure 12) pulmonary hyperinflation, without active lesions. 


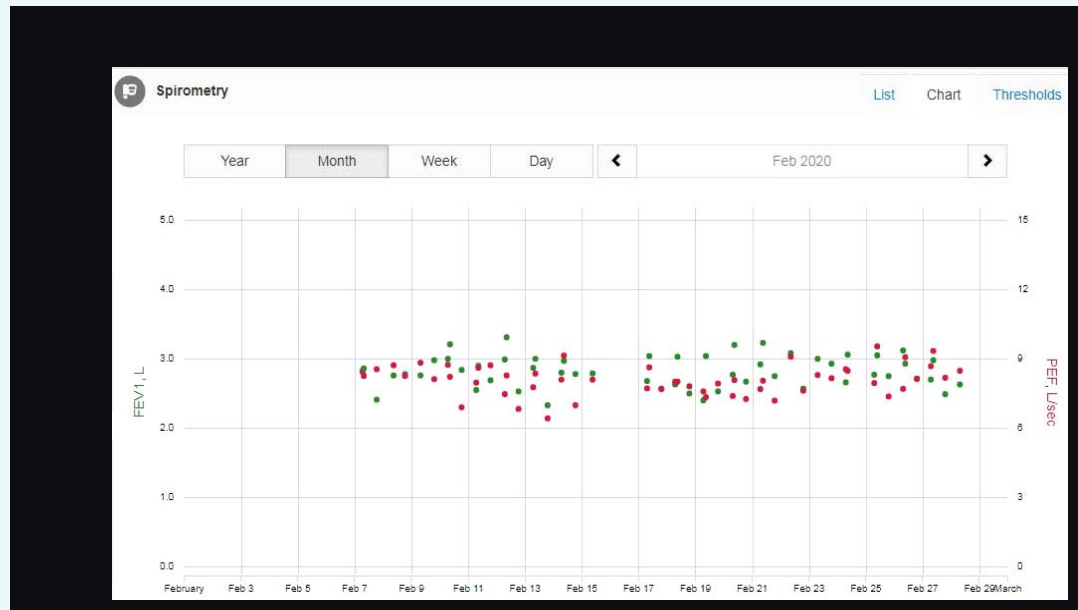

Figure 8a. February

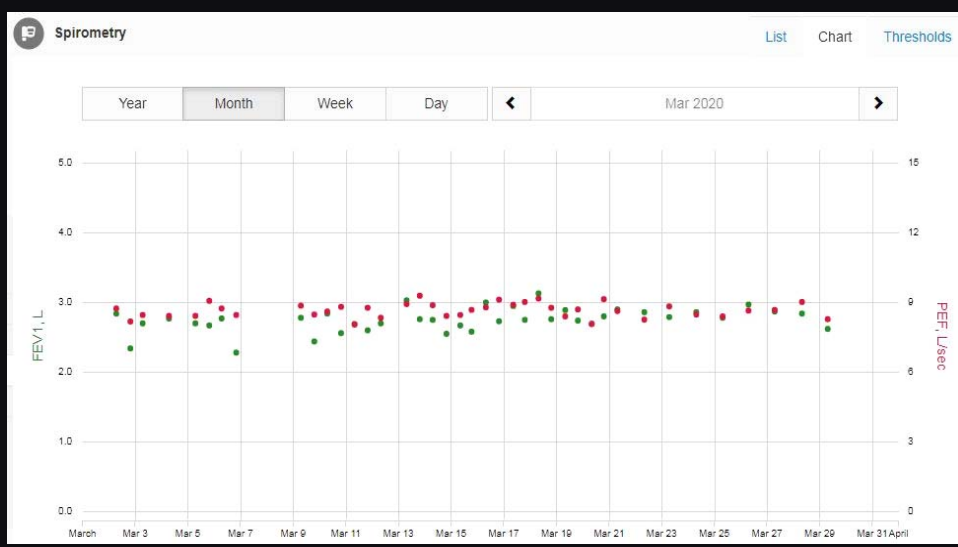

Figure 8b. March

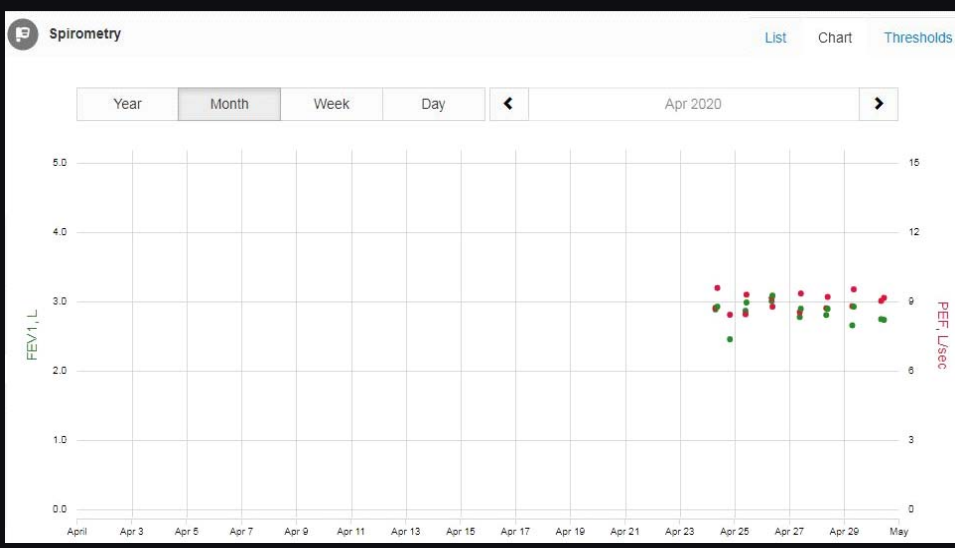

\section{Figure 8c. April}

\section{Distance}

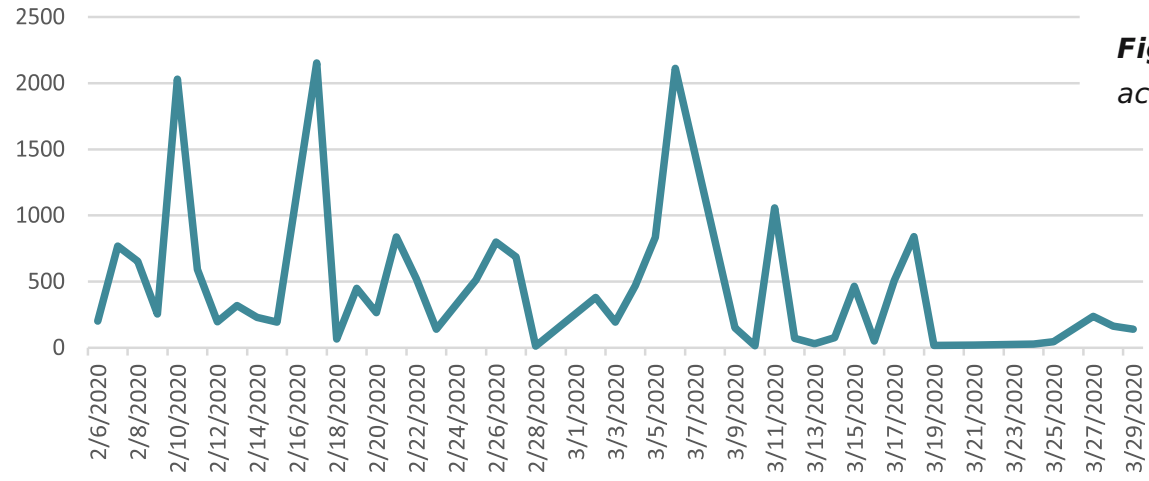

Figure 9. Physical

activity monitoring 


\section{INTERNAL MEDI}

Original papers

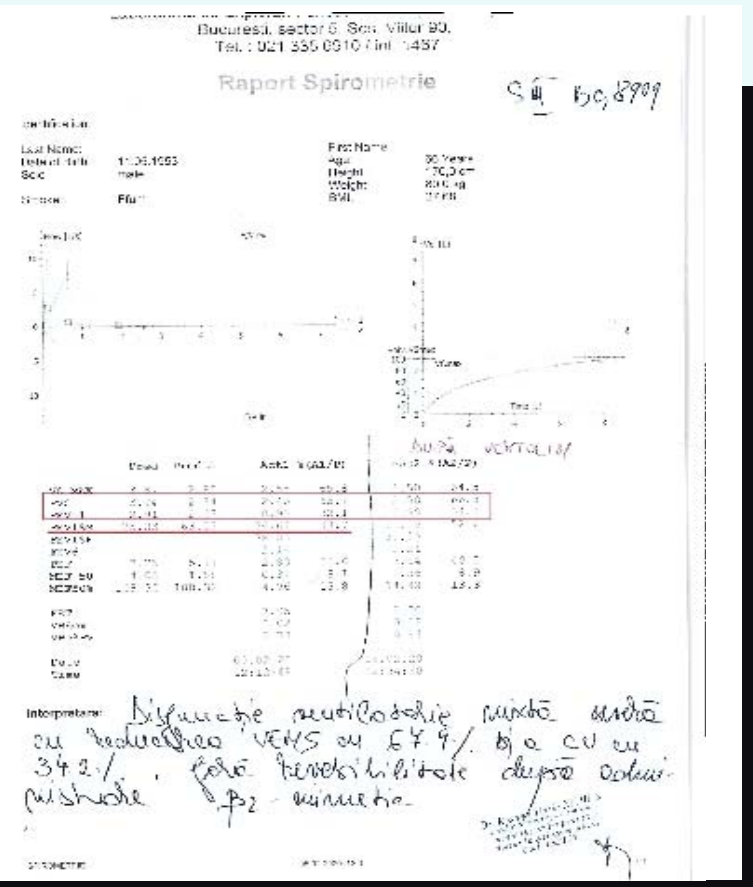

\section{Figure 10. Spirometry}

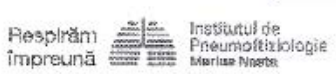

Buletin Analize Medicale

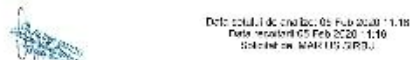

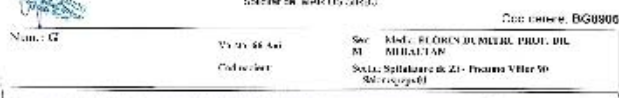

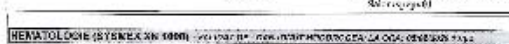

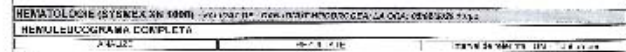

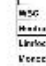

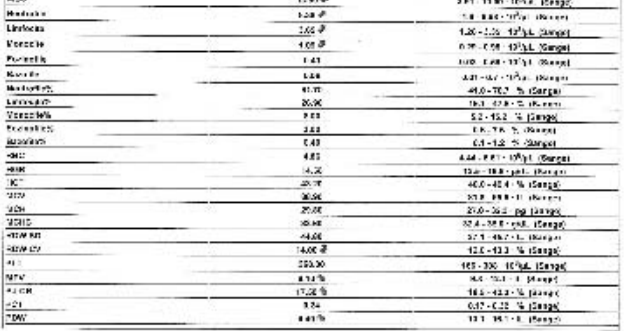

1 ב

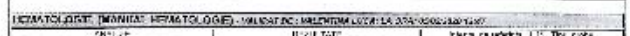
$\sqrt{10 n}$

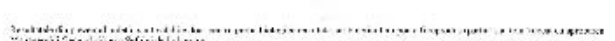

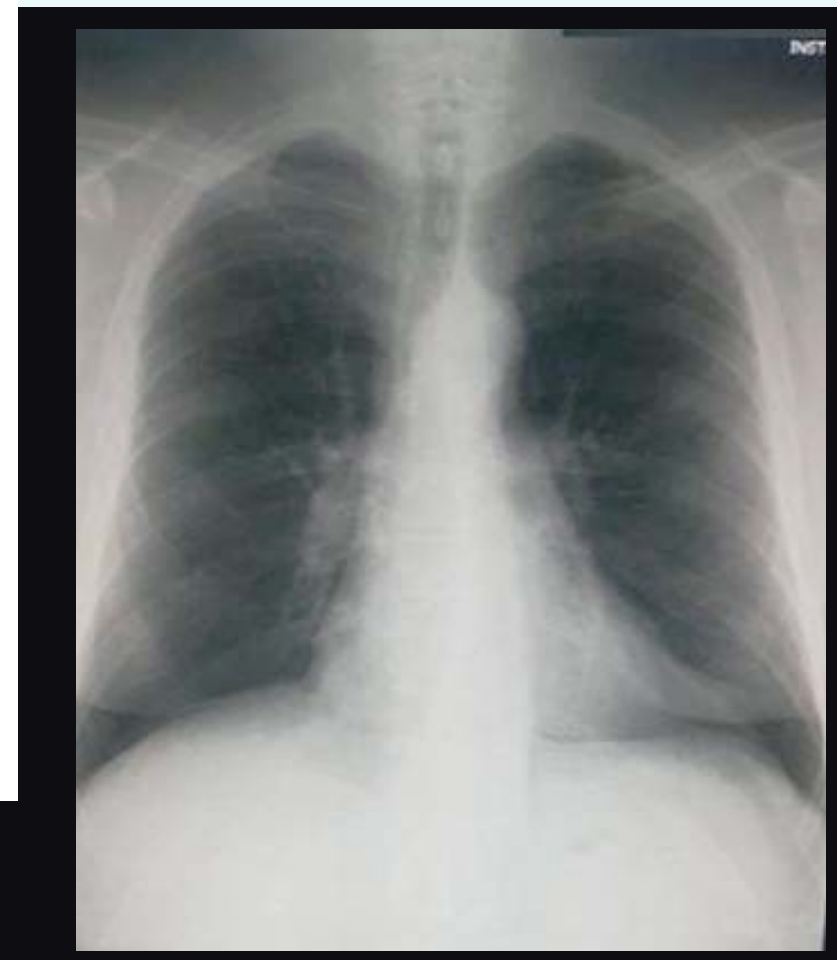

Figure 12. X-Ray evaluation

Figure 11. Medical report 


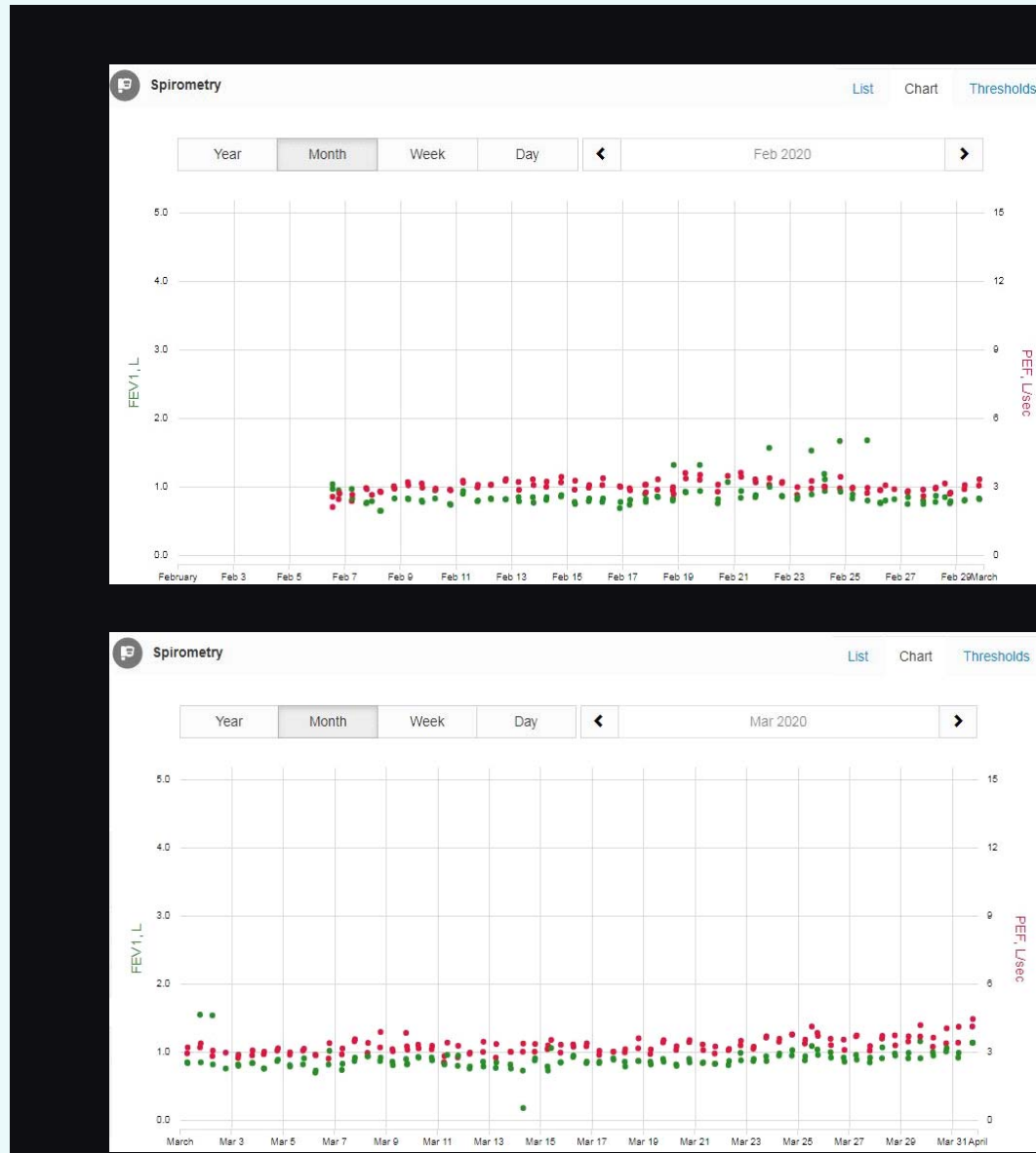

Figure 13a. February

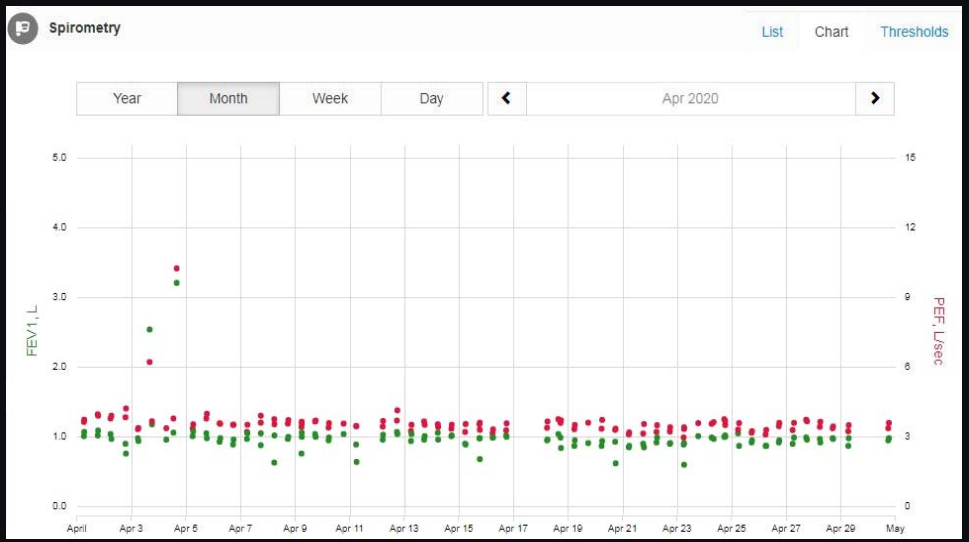

Figure 13b. March

Figure 13c. April

The evolution of the respiratory functional parameters (Figure 13a, b, c) showed that in the 2 and a half months a capping of FEV 1 around 1 liter, without obvious fluctuations. There was added a monitoring of saturation over the same interval (Figure 14a, b, c) which showed that saturation fluctuated between $94-96 \%$ but also with sporadic values below $92 \%$.
Physical activity monitoring instead, reconfirmed a decrease in the number of steps from an average of 2,500 to an average of 1,500 , caused by the enforce of quarantine.

He had an anxious syndrome, but the the phone calls, every 2 days, and the follow-up of the functional parameters and the saturation, allowed a stable mental balance 


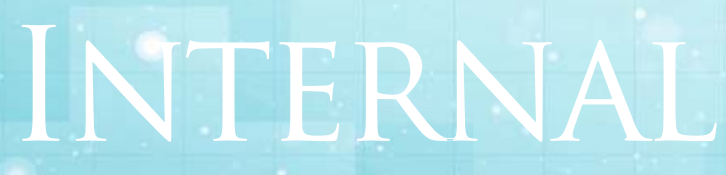

Original papers

without without the need for its presencein the emergency department (Figure 15).

\section{Discussion}

When telemonitoring as a tool was imagine, the most important objectives were: to avoid useless hospital and emergency department admissions, to reduce general practitioner and specialist visits, to improve the quality of life, and to involve the patients and their families $^{(3,4)}$.

There are many large studies about telemonitoring in COPD. One example is PROMETE I and II trial. PROMETE II concluded that telemonitoring did not reduce the admission to the emergency department and hospitalizations (this was the first objective on all studies).

Having only telehealth physiological monitoring of severe COPD, for a long term, will unlikely be of benefit ${ }^{(5)}$. PROMETE I, had other results at the opposite. After 7-month of monitoring of elderly, severe COPD patients, and realizing a follow-up they found a significant reduction of hospitalization, periods of stay on mechanical ventilation, and visits to the emergency department, confirming the practicality of telehealth assistance for these type of severe COPD patients $^{(6)}$.

The most challenging problem remains early identification of exacerbation in COPD patients. At the same time these telehealth technologies are increasing patient activation and empowerment, facilitating the collaboration between patients and healthcare professionals. Self-management seems to be another problem to be solved with the help of telemedicine ${ }^{(7,8)}$ but we need to standardize the way symptoms ${ }^{(9)}$. The final hope is helping patients to be more adherent in problem-solving and decision making. Our three cases are emblematic. Case number one, a COPD stage II, B, with arterial hypertension as the only comorbidity, succeeded in this social isolation period to rise his FEV1 (probably this triple therapy action was important) but with an important diminishing of the physical activity and became an important candidate to muscle deconditioning.

Case number 2, another COPD stage II, B but with multiple comorbidities (diabetes mellitus, arterial hypertension, obesity, sleep apnoea syndrome) kept his FEV1 at similar values and also diminished his physical activities to a very low level.

Case number three was the most severe case with a COPD stage IV(D) with maximal therapy, including long term oxygen therapy and CPAP but also a lot of comorbidities (arterial hypertension, arterial fibrillation, coronary disease, anxiety syndrome). He succeeded to keep his FEV1 at 1 I even if the physical activity diminished, but not so 


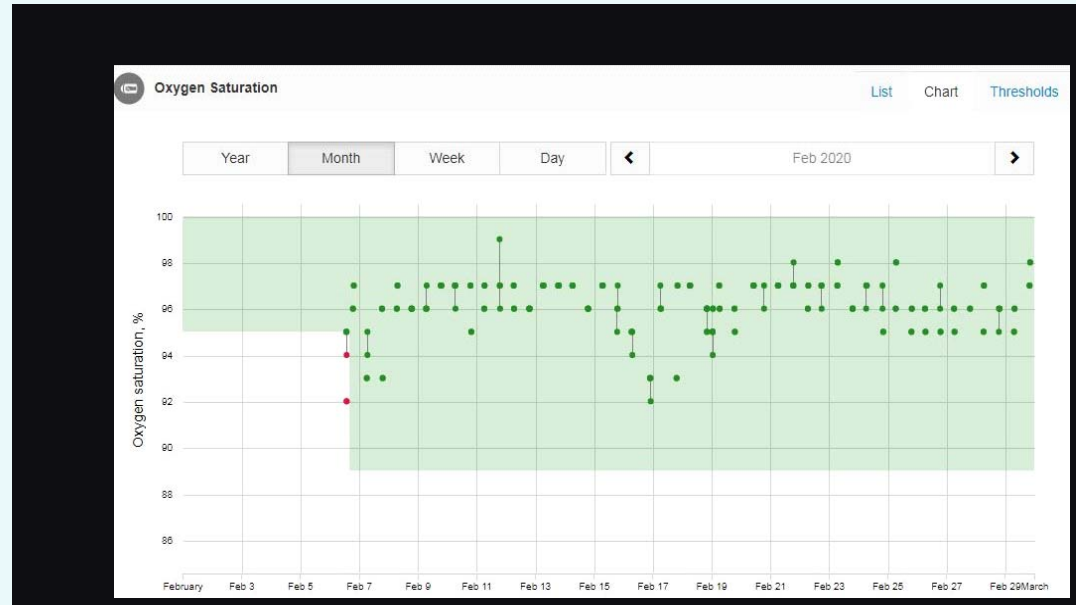

Figure 14a. February

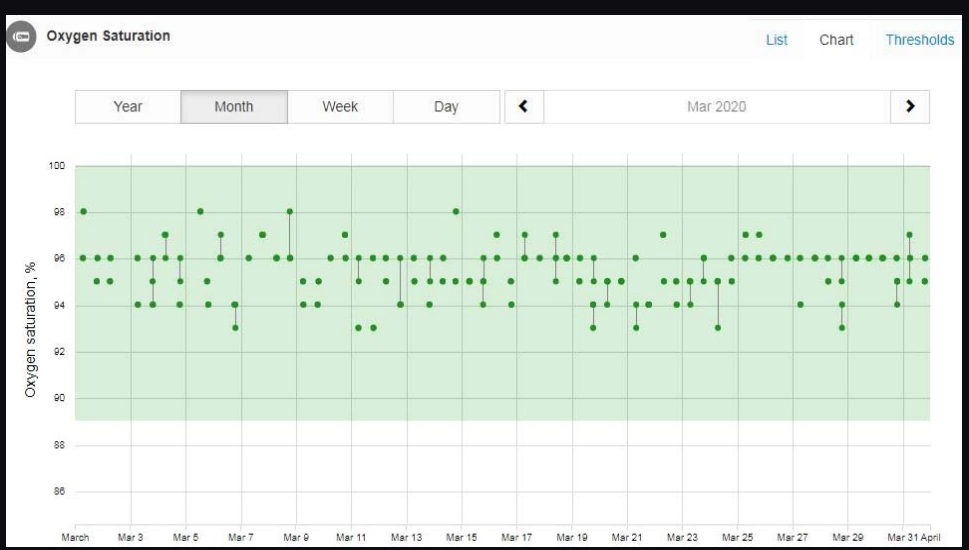

Figure 14b. March

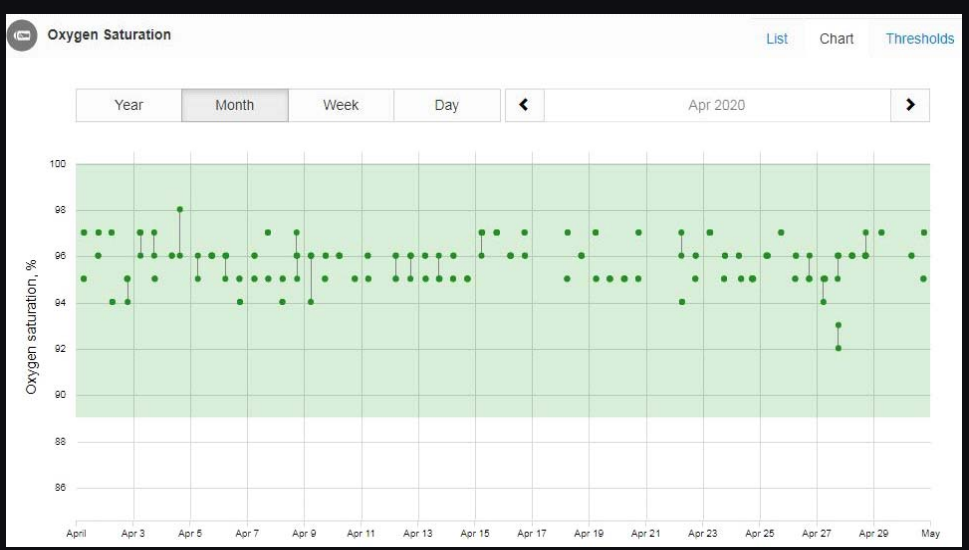

Figure 14c. April

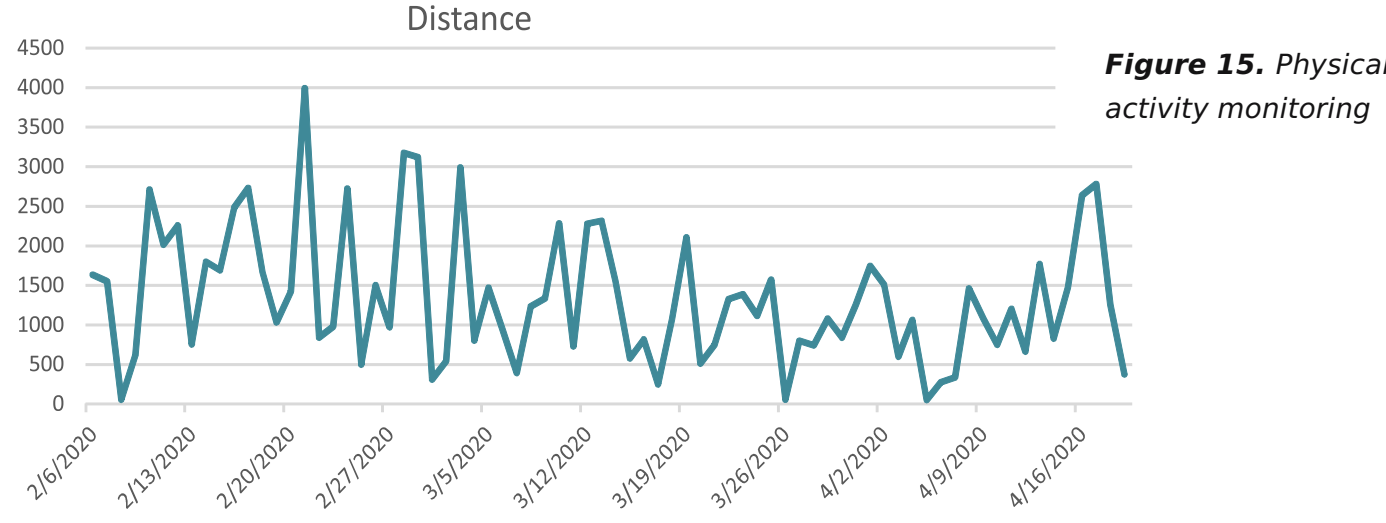




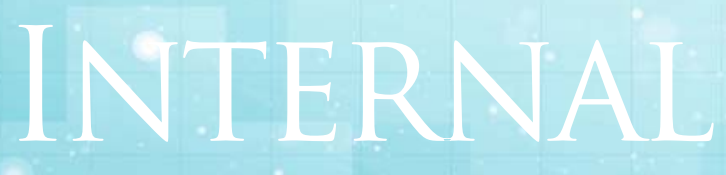

Original papers

spectacular as in the other two cases. Keeping in touch by phone keeps away this patient form the emergency service.

What was important for all COPD patients? They didn't catch any COVID 19 infection because they were monitored at home efficiently in a peak moment of COVID 19 infection in Romania. This secured our patients.

Another important aspect to be discussed is the effect of the quarantine period imposed by this exceptionally, unexpected springtime event, the pandemic coronavirus infection. It is thus not surprising to find a worse prognosis of Covid-19 in patients with COPD.

It's well known now that the risk of severe Covid-19 in a patient with pre-existing COPD was 4-fold higher than in patients without COPD (10). All the experts recommend for COPD patients two things: strong efforts directed to avoid infection in patients with underlying COPD and strict control of Covid19 spread combined with an urgent need for mitigation strategies in patients with preexisting COPD.

Telemedicine is rediscovered and became in this new context a strong weapon for protecting our COPD patients. Coming back to our three cases we must recommend adding daily physiotherapy and more physical activity in this quarantine period. Exercise itself cannot reverse COPD, but it can change the way of feeling, breathing, and functioning of our patients. The limits of our study where the small number of cases. In real life, our article is another proof of the benefits of long term surveillance of COPD patients in a quarantine period.

\section{Conclusions}

Despite the limited evidence on quarantine state in order to control COVID-19 pandemic evolution, studies consistently concluded that quarantine is and remains an important public health measure to reduce the number of people infected and the number of deaths ${ }^{(11)}$. For COPD patients it is also important to be more protected in this period and telemonitoring remains an important surveillance tool not only for adherence to therapy, for early identifying an exacerbation but also for evaluating the physical activity impact when they are blocked at home by this social and physical distancing recommendation.

\section{References}

1. J. Matusitz, G.-M. Breen, Telemedicine: its effects on health communication, Health Commun. 21 (2007) 73-83, http://dx.doi.org/10.1080/10410230701283439. 2. R.L. Bashshur, G.W. Shannon, B.R. Smith, D.C. Alverson, N. Antoniotti,W.G. Barsan, N. Bashshur, E.M. Brown, M.J. Coye, C.R. Doarn, S. Ferguson, J. Grigsby, E.A. Krupinski, J.C. Kvedar, J. Linkous, R.C. Merrell, T. Nesbitt, R. Poropatich, K.S. Rheuban, J.H. Sanders, A.R. Watson, R.S. Weinstein, P. Yellowlees, The empirical foundations of telemedicine interventions for chronic disease 
management, Telemed. J. E-Health Off. J. Am. Telemed. Assoc. 20 (2014),769-800, http://dx.doi.org/ 10.1089/tmj.2014.9981

3. Ambrosino N, Vagheggini G, Mazzoleni S, Vitacca M. Telemedicine in chronic obstructive pulmonary disease. Breathe 2016; 12: 350-356

4. Mihălțan FI, Coșei V., Borcea C., Ancuța CTelemedicine in chronic obstructive pulmonary disease: a possible transition to the patient independencePneumologia (in press) -2020-0006 692020 1-5

5. Ancochea J, García-Río F, Vázquez-Espinosa E, HernandoSanz A, López-Yepes L, Galera-Martínez R, et al. Efficacy and costs of telehealth for the management of COPD: the PROMETE II trial. European Respiratory Journal. 2018;51(5): pii:1800354.

6. Segrelles Calvo G, Gómez-Suárez C, Soriano JB, Zamora E, Gónzalez-Gamarra A, González-Béjar M, et al. A home telehealth program for patients with severe COPD: the PROMETE study. Respiratory Medicine. 2014;108(3): 453-462

7. Lenferink $A$, Brusse-Keizer $M$, van der Valk $P D$, et al. Self-management interventions including action plans for exacerbations versus usual care in patients with chronic obstructive pulmonary disease. Cochrane Database Syst Rev 2017; 8: CD011682.

8. Criner GJ, Bourbeau J, Diekemper RL, et al. Prevention of acute exacerbations of COPD: American College of

Chest Physicians and Canadian Thoracic Society Guideline. Chest 2015; 147: 894-942.

9. Bourbeau J, Farias R. Making sense of telemedicine in the management of COPD. Eur. Respir J 2018; 51 : 1800851 [https://doi.org/10.1183/13993003.008512018].

10. Zhao Q, Meng M, Kumar R, et al. The impact of COPD and smoking history on the severity of Covid-19: A systemic review and meta-analysis [published online ahead of print, 2020 Apr 15]. J Med Virol. 2020;10.1002/jmv.25889. doi:10.1002/jmv.25889

11. Nussbaumer-Streit_B, Mayr_V, Dobrescu_Al, Chapman_A,Persad_E, Klerings_I, Wagner_G, Siebert_U, Christof_C, Zachariah_C, Gartlehner_G.-Quarantine alone or in combination with other public health measures to control COVID-19: a rapid review. Cochrane Database of Systematic Reviews 2020, Issue 4. Art. No.: CD013574. DOI: 10.1002/14651858.CD013574. 